\title{
Pathways of Mesoscale Variability in the South China Sea
}

\author{
ZHUANG Wei ${ }^{1 *}$, DU Yan ${ }^{1}$, WANG Dongxiao ${ }^{1}$, XIE Qiang $^{1}$, XIE Shang-Ping $^{2}$
}

1. Key Laboratory of Tropical Marine Environmental Dynamics, South China Sea Institute of Oceanology, Chinese Academy of Sciences, Guangzhou 510301, China

2. International Pacific Research Center and Department of Meteorology, University of Hawaii, Honolulu, Hawaii, USA)

Chinese Journal of Oceanology and Limnology

January 29, 2010, submitted

May 14, 2010, revised

June 03, 2010, accepted

* Corresponding author: ZHUANG Wei, email address: zhuang@scsio.ac.cn 
Abstract: The propagation of oceanic mesoscale signals in the South China Sea (SCS) is mapped from satellite altimetric observations and an eddy-resolving, global ocean general circulation model by using the maximum cross-correlation (MCC) method. Significant mesoscale signals propagate along two major bands of high variability. The northern band is located west of the Luzon Strait, characterized by southwestward eddy propagation. Though eddies are the most active in winter, their southwestward migrations exist throughout the year, steered by bathymetry. Advection by the mean flow plays a secondary role in modulating the propagating speed. The southern eddy band lies in the southwest part of the SCS deep basin and is oriented in an approximately meridional direction. Mesoscale variability propagates southward along the band in autumn. This southward eddy pathway could not be explained by mean flow advection and is likely related to the eddy detachments from the western boundary current due to nonlinear effects. Our mapping of eddy propagation velocities provides important information for further understanding eddy dynamics in the SCS.

Key words: sea level; mesoscale variability; maximum cross-correlation; SCS 


\section{Introduction}

The South China Sea (SCS) is a semi-enclosed marginal sea of the western Pacific, connecting in the south with Java Sea through the Karimata Strait and in the northeast with Pacific through the deep Luzon Strait (Figure 1). The bathymetry of the SCS is complex with a deep basin in the center elongating in the northeast-southwest direction and numerous islands and reefs around the basin. The climate of SCS is a part of the East Asian monsoon system (Wyrtki, 1961). Driven by the monsoonal winds, the oceanic circulation in the upper layer exhibits strong seasonal variability, predominantly cyclonic in winter and anticyclonic in summer (Liu et al., 2001b; Wang et al., 2003a). In the northern SCS (NSCS), the circulation is greatly affected by the Kuroshio intrusion (e.g. Shaw, 1991), which appears to be a transient phenomenon related to the interaction between Kuroshio and eddies (Jia et al., 2005; Yuan et al., 2006). But the dynamical interior is still not fully understood.

Mesoscale fluctuations on temporal-spatial scales between 20-150 days and 50-500 km dominate the oceanic variability (Wyrtki et al., 1976; Richman et al., 1977) and are largely accounted for by eddies (Chelton et al., 2007). In the SCS, besides seasonal variability, the circulation also displays energetic mesoscale variability (MV). Multi-scale eddies embedded in the circulation are observed from different hydrographic datasets ( $\mathrm{Xu}$ et al. 1982; Chu et al., 1998) and reproduced by eddy-resolving numerical models (Metzger, 2003; Gan et al., 2006). The application of the satellite altimetry enhanced our understanding of MV in the SCS to a new 
epoch. Based on along-track altimetry data, significant MV in the SCS is considered to be along two bands north of $10^{\circ} \mathrm{N}$ : the stronger one lies along the northwestern boundary west of the Luzon Strait and the weaker one is oriented in a NE-SW direction across the central basin (Wang et al., 2000). The propagations of MV are widely observed in the SCS. Using the buoys and altimetry observations, Liu et al. (2001a) note the importance of eddy movements to the intraseasonal variability of the thermocline in the central SCS. The synergy of satellite observations and model simulations indicates that the high-frequent sea level variations in deep basin are mainly attributed to flow instabilities and tend to propagate along high-variance bands (Zhuang et al., 2010). The geographical distributions and tracks of eddies are firstly depicted by Wang et al. (2003b) based on a merged altimetry dataset. Following this work, recently Xiu et al. (2010) describe various eddy characteristics in the SCS using numerical study and show the westward tendency of eddy trajectories.

Near the Luzon Strait, Li et al. (1998) record the evidence of anticyclonic eddies in the NSCS and treat the eddies as Kuroshio origin. Although strong 3-6 months MV exists both in the NSCS and the western Pacific (Hu et al., 2001), Kuroshio appears to act as a barrier to the westward propagations of MV from the Pacific and only 45-day MV could enter the SCS via the Luzon Strait (Li et al., 2007). The investigation by Wu and Chiang (2007) also shows that the westward propagating eddies in the NSCS originate near the Luzon Strait rather than coming from the western Pacific. These studies have improved our understanding on the transient MV and associated eddy activities in the SCS. 
Despite above studies on the movements of MV and eddies, a general pattern of the MV propagations in the SCS has not been given. Previous studies on the movement of eddies are based on visual tracking of identifiable features in time sequence of sea surface height (SSH) maps (e.g. Wang et al., 2003; Xiu et al., 2010). Extending previous studies on Lagrangian tracking of individual eddies, the present study applies a space-time lag correlation technique to provide a high-resolution Eulerian description of eddy pathways, by using merged altimetry data and simulations by an eddy-resolving, global ocean general circulation model (OGCM). The results show important effects of wave propagation, mean circulation, bathymetry and nonlinear processes. The remainder of the paper is organized as follows. Section 2 describes observational data and model output. The approach to estimate propagation velocity is also briefly introduced here. Section 3 presents the annual and seasonal pathways of mesoscale signals. Discussion and summary are given in Section 4 and Section 5, respectively.

\section{Data and Methods}

\subsection{Observational data}

Sea level anomalies (SLAs) have been measured by multi-satellite altimeters for more than one decade. The estimation of mesoscale signals is greatly improved when the data from two satellites are combined with the use of an objective mapping technique (Ducet et al., 2000). Compared to the results obtained with 2 altimeters, the MV estimated with 4 satellites has little improvement at low latitudes, where the size 
of typical structures is relatively large (Pascual et al., 2006). It is known that altimetry measurements could be contaminated by high-frequency (HF) variability at period shorter than the Nyquist period of altimetric repeat cycle. These unresolved HF signals are mainly tides (e.g. Schlax and Chelton, 1994) or barotropic variability induced by HF atmospheric forcing (e.g. Fukumori et al., 1998). In 2005, the multi-mission altimeter data set is updated with new corrections using an up-to-date tidal model (GOT2000, Goddard/Grenoble Ocean Tide) and a new barotropic model (MOG2D-G, Modèle aux Ondes de Gravité 2-Dimensions Global), which largely suppressed the HF aliasing signals (Carrère and Lyard, 2003, Lyard et al., 2006).

In this study, we use the newly released altimetry dataset. Volkov et al. (2007) compare the new version with previous altimetry products and find that it makes much better tidal and atmospheric barometric corrections. The improved accuracy enables the study of MV variability even over some continental shelves. To keep the sampling homogeneous, we adopt the merged SLA data derived from simultaneous measurements of two satellites (Topex/Poseidon or Jason-1 + ERS or Envisat). The product is distributed by AVISO and consists of maps since October 1992 with 7-day time intervals and the Mercator $1 / 3^{\circ}$ spatial resolution. The data from 2000-2008 are analyzed for comparison with the OGCM simulations. To avoid possible residual aliasing, the data over the shelves shallower than $100 \mathrm{~m}$ are masked out in this study.

To show the basin-scale geostrophic currents, we use the absolute dynamic topography (ADT), which consists of a mean dynamic topography (MDT) and the altimetric SLAs. The method on the estimation of MDT is introduced by Rio et al. 
(2005). The ADT data are also distributed by AVISO with the same resolution as SLAs. The ADT represents the sea level above the geoid, while the simulated free surface is referred to global mean SSH. Within the SCS domain, the regional annual mean values of ADT and simulated SSH are 229.9 and $62.3 \mathrm{~cm}$, respectively. Their difference $(167.6 \mathrm{~cm})$ is subtracted from ADT for easy viewing on comparisons. It will not change the spatial gradient of ADT and the associated geostropic currents.

\subsection{Product from the eddy-resolving model}

The satellite observations are compared with the product from an eddy-resolving OGCM for the Earth Simulator (OFES; Masumoto et al., 2004). The model is based on the Modular Ocean Model (MOM3; Pacanowski and Griffies, 2000 ), with a near-global domain extending from $75^{\circ} \mathrm{S}$ to $75^{\circ} \mathrm{N}$. Horizontal resolution is $0.1^{\circ} \times 0.1^{\circ}$. There are 54 vertical Z-coordinate levels, with varying resolutions from $5 \mathrm{~m}$ at the surface to $330 \mathrm{~m}$ at the maximum depth of $6065 \mathrm{~m}$.

Following a 50-year spin-up integration with monthly climatological forcing, a hindcast simulation from 1950-2005 is conducted with surface wind stress, heat, and freshwater fluxes derived from the daily mean NCEP/NCAR reanalysis (NCEP run hereafter). In addition, sea surface salinity is restored to the monthly climatology of World Ocean Atlas 1998. Another hindcast run starts from the NCEP run on 20 July 1999 but is forced by daily mean surface wind stress from QuikSCAT measurements (QSCAT run). Other atmospheric forcings are the same as those in the NCEP run (Sasaki et al., 2006). This study uses the output of QSCAT run, whose performance is better than the NCEP run because of high resolution and accuracy of the wind forcing 
(Zhuang et al., 2010). The 3-day snapshots of SSH during 2000-2008 are applied in this study.

To extract MV, the annual and semiannual cycles are firstly removed using a harmonic filter. It is because they are not mainly induced by eddy activities but by direct atmospheric forcing including Ekman pumping, wind stirring and cooling convection (Qu et al., 2007). To examine the significant periods of the residual signals, we select two locations (denoted with green triangles in Figure 3a) where eddy occurrences are high (Xiu et al., 2010) and analyze the power spectra of residual SSH. The results of both altimetry and OFES indicate that the 30-180 days signals are often above $95 \%$ confidence level, while other signals with lower and higher frequencies are not significant at the $95 \%$ level (Figure 2). The signals with periods shorter than 30 days are relatively weak. Besides, considering different temporal resolutions for altimeter and OFES data (7 days and 3 days, respectively), we select their common multiple (21 days) as the cutoff period. So a 21-175 days band-pass filter is used to remove the low-frequent variability and suppress synoptic disturbances with periods shorter than 20 days. An additional harmonic filter is then applied to remove the possible tidal aliasing near 60-day (Li et al., 2007). This frequency band is similar to the MV definition in Wang et al. (2000) except that they have to remove all signals shorter than 60 days due to strong tidal aliasing in previous altimetry products.

\subsection{The maximum cross-correlation technique}

The maximum cross-correlation (MCC) method is a space-time lagged 
technique for detecting translational motions from time-sequential remote sensing data, and has been commonly used to estimate motion velocities of some spatial or temporal features (Emery et al., 1986; Domingues et al., 2000; Fu, 2006). This method is used to estimate the speed and direction of mesoscale signals in this study. At a given location $\left(x_{0}, y_{0}\right)$, the cross-correlations of the sea level MV with neighboring sea level MV within a certain range are calculated for some time lags. At each time lag $(\Delta T)$, the position of maximum correlation is identified and a velocity could be estimated from the time lag and the distance $(\Delta x, \Delta y)$ of the position from the origin. An average velocity vector $(u, v)$ weighted by the correlation coefficients is then calculated from the estimates at various time lags as

$$
\left(u\left(x_{0}, y_{0}\right), v\left(x_{0}, y_{0}\right)\right)=\frac{\sum_{i}\left(\Delta x_{i} / \Delta T_{i}, \Delta y_{i} / \Delta T_{i}\right) C_{i}}{\sum_{i} C_{i}}
$$

Where $C_{i}$ is the maximum correlation at $\Delta T_{i}$, and $\Delta x_{i}, \Delta y_{i}$ represent the distance between the location of maximum correlation and the origin. The average velocity is assigned to the propagation velocity of MV at the given grid $\left(x_{0}, y_{0}\right)$.

To focus on the mesoscale and reduce the incidence of spurious MCC vectors, the maximum possible velocity is set at $26 \mathrm{~km} /$ day $(30 \mathrm{~cm} / \mathrm{s})$, which is generally larger than the propagation speeds of eddies (Chelton et al., 2007). Meanwhile, the phase speeds of baroclinic Rossby waves are mostly lower than $30 \mathrm{~cm} / \mathrm{s}$ as well (Gan and Cai, 2001). The exception only exists in the southeast basin, where, as will be shown later, has weak MV and is dynamically unimportant to this study. Therefore, the movements of most MV could be well captured under this speed limitation. The area 
involved in computation broadens with increasing time lags to meet the velocity limit. The minimum acceptable correlation coefficient should be above 95\% confidence level on the basis of $t$-test. The time lags are limited to less than 42 days. At larger time lags, many correlation coefficients are below the $95 \%$ confidence level. In this study, four seasons are defined as below: winter (December to February), spring (March to May), summer (June to August) and autumn (September to November). Apparently, when calculating the velocities in each season, the time series are not smoothly connected. We treat each continuous 3 months (1 season in a specific year) as a group for all time series. In the calculation of lead-lag correlation between 2 time series, only the data in the same groups are involved into the comparison.

\section{Results}

\subsection{The annual mean pattern}

Displayed in color shading in Figure 3 (a) is the standard deviation of sea level MV measured by the satellite altimeters, showing the annual mean intensity of eddy variability. The MV is weak in the southeastern basin and forms two strong bands in the northern and western SCS. The northern high-variance band west of the Luzon Strait is also observed by Wang et al. (2000). The southern one locates near the western SCS, instead of being oriented in the northeast-southwest direction across the basin as marked in Wang et al. (2000). The discrepancy is probably due to the low resolution of single satellite measurements in Wang et al. (2000), especially in the cross-track direction. East of the Luzon Strait, large MV is also observed. The 
high-variance zones in the western Pacific and the NSCS are not continuous but separated by low values at the Luzon Strait. The distribution is consistent with the eddy occurrence areas estimated by Xiu et al. (2010) and similar to the intraseasonal variance of SSH in deep waters, a sign of eddy activities (Zhuang et al., 2010). Superimposed on the variance fields are the propagation velocities of mesoscale signals. Within two high-variance bands in the interior SCS, vectors is mainly oriented southwestward, suggesting the eddy propagations along both bands. The band orientation and velocity directions match better in the northern band than in the southern one. Away from the energetic zones, essentially westward propagations of MV signals are found in the region north of $12^{\circ} \mathrm{N}$, in good agreement with the trajectories of eddies originated west of the Luzon Island (Wang et al., 2003). Around the Nansha Islands (east of $112^{\circ} \mathrm{E}, 6-12^{\circ} \mathrm{N}$ ), the $\mathrm{MV}$ is the weakest and the propagation trend becomes ambiguous. OFES simulations generally reproduce not only the mesoscale variances of SSH but also their propagating features (Figure 3b). A difference on the variance pattern exists near $\left(111^{\circ} \mathrm{E}, 14^{\circ} \mathrm{N}\right)$, where the observed active MV center is not captured by OFES. As will be shown in Section 3.2, this disagreement mainly results from a difference during spring to summer.

To illustrate the effects of mean flow on the eddy propagations, we superimpose the MV propagation velocity on the ocean dynamic topography (Figure $3 \mathrm{c}, \mathrm{d})$. In the western Pacific, the westward propagations dominate the vast region east of $128^{\circ} \mathrm{E}$. Toward the western boundary, propagation velocities are significantly affected by Kuroshio and Mindanao Current. The vectors bifurcate into two branches 
at $13-14^{\circ} \mathrm{N}$ and eddies are carried northward/southward by Kuroshio/Mindanao Current. The majority of northern branch leaps across the Luzon Strait to the east of Taiwan Island. There is no direct westward signal propagation through the Luzon Strait. Only a few vectors show weak northwestward trends into the SCS following the path of Kuroshio. In the interior SCS, the annual mean circulation pattern is a weak cyclonic gyre occupying the northern basin. To the south of the NSCS continental slope, the MV signals show obvious migrations along 200-2000 m isobaths from southwest of Taiwan Island toward the western SCS, suggesting the steering effects of the bathymetry.

To further clarify the eddy propagations near the Luzon Strait and the NSCS, we select a strip along the northern energetic band and extend it across the Luzon Strait to the Pacific (shown as dashed line in Figure 3a). The meridionally averaged velocities along the strip show westward propagations on both sides of the strait (Figure $4 \mathrm{a}-\mathrm{b}$ ). But the propagation velocities diminish to nearly zero at $122^{\circ} \mathrm{E}$ and $121^{\circ} \mathrm{E}$ in observations and simulations, respectively. It suggests that the directly westward propagation from the Pacific to the NSCS is not significant (Li et al., 2007).

In the southern high-variance band, the energetic MV signals do not move eastward along the path of the mean flow but propagate southwestward (Figure $3 \mathrm{c}, \mathrm{d}$ ), probably due to the ocean adjustments discussed in the next section. To the east of the Vietnam coast, low propagation velocities are found at the latitude of $10-15^{\circ} \mathrm{N}$, associated with weak annual mean western boundary current. 


\subsection{Seasonal variations}

Pronounced seasonal cycle of the SCS circulation and its forcing mechanisms have been studied for decades. Figure 4 reveals that eddy propagations along both high-variance bands also exhibit obvious seasonality. Along the northern band, the propagation of MV keeps westward throughout the year. The observed results (Figure 4a) show that, despite clear spatial variations, mean along-band speed between $111^{\circ} \mathrm{E}$ $-119^{\circ} \mathrm{E}$ peaks in winter $(8.7 \mathrm{~cm} / \mathrm{s})$, decreases during spring $(7.9 \mathrm{~cm} / \mathrm{s})$, reaches minimum in summer $(5.4 \mathrm{~cm} / \mathrm{s})$ and then increases during autumn $(6.2 \mathrm{~cm} / \mathrm{s})$. OFES captures this seasonality with corresponding velocities at $8.4,7.2,4.2$ and $5.9 \mathrm{~cm} / \mathrm{s}$, respectively (Figure 4b). Along the southern band, the eddy propagations present more significant seasonal variability (Figure $4 \mathrm{c}-\mathrm{d}$ ). Both observations and simulations suggest that, averaged between $6^{\circ} \mathrm{N}-14^{\circ} \mathrm{N}$, the southward movement of MV is the fastest in autumn $(8.1 \mathrm{~cm} / \mathrm{s}$ and $6.5 \mathrm{~cm} / \mathrm{s})$, slowing down from winter $(2.3$ $\mathrm{cm} / \mathrm{s}$ and $5.4 \mathrm{~cm} / \mathrm{s})$ to spring $(1.4 \mathrm{~cm} / \mathrm{s}$ and $1.9 \mathrm{~cm} / \mathrm{s})$ and turning northward in summer $(0.4 \mathrm{~cm} / \mathrm{s}$ and $1.0 \mathrm{~cm} / \mathrm{s})$. To the south of $10.5^{\circ} \mathrm{N}$, the observations and simulations display similar seasonality. But at $10.5^{\circ} \mathrm{N}-14^{\circ} \mathrm{N}$, the simulated speed in autumn is lower than that in winter. To further elucidate the above seasonal characteristics, the whole propagation maps in each season will be presented in the following, together with the MV amplitudes and mean dynamic height.

During winter, the basin-scale circulation is cyclonic. The lowest SSH located northwest off the Luzon Island (Figure $5 \mathrm{c}$-d). Associated with strong mean flow, eddy propagations along the northern band are the quickest and the mesoscale variance also 
reaches its maximum (Figure 5a-b). Along the southern band, MV is relatively weaker, which is the remnant of strong variability in autumn. The simulated MV is stronger in amplitude and propagates faster than the observation (Figure 5a-b and Figure $4 \mathrm{c}-\mathrm{d}$ ). The overestimate of MV in OFES is possibly due to the undervaluation of dissipation rate in the model. In the eastern SCS, Wang et al. (2008) argue that, during the winter monsoon, orographic wind jets spin up alternating clusters of cyclonic and anticyclonic eddies. The vectors in Figure 5 suggest that the local eddy energy driven by Ekman pumping tends to propagate westward under the beta effect, resulting in low MV to the west of the Luzon Island.

The circulation in spring turns weaker due to the decay of northeast monsoon. There only exists a cyclonic gyre to the northwest of Luzon Island (Figure $6 \mathrm{c}-\mathrm{d}$ ). MV along the northern band weakens somewhat but is still active (Figure $6 \mathrm{a}-\mathrm{b}$ ). The maximum center move essentially westward, implying the downstream eddy movement from winter to spring. The observed westward tendency is more significant than the simulated one. Strong mesoscale signals in the altimetric measurements could reach $14^{\circ} \mathrm{N}$ to the east of Vietnam. In the western SCS, MV within the southern band turns much weaker and its propagation speed is low at latitudes $5^{\circ} \mathrm{N}-15^{\circ} \mathrm{N}$ (also see Figure $4 \mathrm{c}-\mathrm{d}$ ). With weak mean flow and eddy activity, westward propagations prevail in the eastern and central basin.

In summer, the southwesterlies are blocked by Annam Cordillera and accelerated to form a wind jet near $10^{\circ} \mathrm{N}$ (Xie et al., 2003). The resultant wind stress curl (WSC) dipole drives a strong anticyclonic gyre to the south and a weak cyclonic 
gyre to the north, with an eastward offshore jet at about $11^{\circ} \mathrm{N}$ (Figure $7 \mathrm{c}-\mathrm{d}$ ). Along the northern band, the mean flow turns eastward, slowing down the propagations of MV. At the same time, the mesoscale fluctuations reduce substantially and form high-variance patches rather than a continuous band (Figure $7 \mathrm{a}-\mathrm{b}$ ). In the western SCS, both observations and simulations show conspicuous MV near $11^{\circ} \mathrm{N}$, which represents the variations of the offshore jet in response to intraseasonal wind pulses via Rossby wave adjustment (Xie et al., 2007). Affected by the offshore jet and the quasi-stationary anticyclonic gyre, the propagation pattern southeast off Vietnam is complex and lack of coherence (also shown in Figure $4 \mathrm{c}-\mathrm{d}$ ). In the observations, there exists another high MV area around $14^{\circ} \mathrm{N}$, which is not reproduced in OFES. It features variability with frequency lower than that along the offshore jet to the south (figure not shown), which is possibly due to the remnant eddy energy from the northern band during spring and/or the eddy propagations from the east.

The monsoon transition from summer to winter regime starts in the NSCS. The mean northeasterly occupies the northern basin during autumn, resulting in strong positive WSC in the north and weak positive WSC in the south of SCS. In response to the surface WSC, the mean circulation exhibits a cyclonic gyre north of $10^{\circ} \mathrm{N}$ (Figure $8 \mathrm{c}$-d). South of the NSCS continental slope, the mesoscale signals grow up in amplitude and accelerate westward in propagating speed (Figure $8 \mathrm{a}-\mathrm{b}$ ). In the western SCS, the southern high-variance band becomes the most active and is oriented in an approximately meridional direction between $6^{\circ} \mathrm{N}$ to $13^{\circ} \mathrm{N}$. The most striking feature is the nearly southward propagation of MV along the southern band, which is 
inconsistent with local northeastward mean flow near $10^{\circ} \mathrm{N}-11^{\circ} \mathrm{N}$. This unique southward eddy motion suggests that the potential vorticity dynamics for the generation of inertia recirculation are probably at work. Due to the asymmetric WSC pattern in the meridional direction, the vorticity input is much larger in the north basin than in the southern part. With the effect of nonlinearity, the vorticity transports of the western boundary current generate southward recirculations and finally form detached eddies. This inertial recirculation theory is presented nicely in Bryan (1963). The detached eddies go on propagating southward, similar to the arrested topographic wave (Csanady, 1978). The amplitude of MV decreases southward remarkably, suggesting the decay of eddies as a result of smaller Coriolis force in the lower latitude.

To validate the reliability of the estimated vectors, the Hovmöller diagrams of mesoscale signals along high-MV bands are plotted. The case in 2004-2005 displays substantial westward eddy movements along the northern band with larger amplitude from winter to spring (Figure 9a). Strong eddies is often generated near the Luzon Strait in winter and migrated to the vicinity of western boundary during spring. Similar propagations could be seen from summer to autumn with lower amplitude. The seasonal variations of eddy propagation speed along the northern band (Figure 4 a-b) suggest possible effects of mean flow advection. Figure 10 shows the simulated flow velocity along the northern band averaged between $111^{\circ} \mathrm{E}-119^{\circ} \mathrm{E}$. The mean flow is northeastward in summer, strongly southwestward in winter and moderately southwestward in spring and autumn, consistent with the seasonality of eddy 
propagation speed. However, the seasonal variability of eddy propagation speed is much weaker than that of surface mean flow, in agreement with previous observations, which suggest that the eddy propagation velocity is several folds less than the surface velocity of mean flow (Fu, 2006). The vertical flow shear is larger in autumn than in spring. Thus in water depth above $127 \mathrm{~m}$, the westward mean flow is stronger in autumn. While below $127 \mathrm{~m}$, the current velocity becomes larger in spring. The higher eddy propagation speed in spring indicates that mean flow below $127 \mathrm{~m}$ has stronger impact on the eddy movements. During summer, the mean flow turns northeastward but the eddy propagation remains southwestward, albeit at reduced speeds. Such an all-year-round southwestward eddy propagation suggests that eddy motions along the northern band are dominated by wave propagation. The mean flow advection plays a secondary role in reducing the speed from about $8.5 \mathrm{~cm} / \mathrm{s}$ in winter to nearly $5 \mathrm{~cm} / \mathrm{s}$ in summer.

Along the southern band, the latitude-time diagram shows that the southward eddy propagations exist mainly in autumn rather than other seasons (Figure 9b). Comparing Figure $6(\mathrm{c}-\mathrm{d})$ with Figure $8(\mathrm{c}-\mathrm{d})$, we could see that to the south of $10^{\circ} \mathrm{N}$, the seasonal mean flows are both weak in spring and autumn. But the southward eddy migrations are much more active in autumn, indicating that the advection by mean flow has limited impact on the MV propagations along the southern band. We also note that the eddy propagations in 2005 are more significant than that in 2004 . The difference between two years indicates the significance of the interannual variability, which deserve a study in the future. 


\section{Discussion}

The seasonal distributions of eddy kinetic energy (EKE) in the SCS are mapped in some previous studies (e.g. He et al., 2002; Chen et al., 2009), which suggest a high-EKE spot east of Vietnam during the period from summer to autumn and another one west of the Luzon Strait in winter. But their results do not exhibit similar high-EKE bands identified in the present study. The discrepancy can be attributed to different definitions on "eddy". In previous studies, the seasonal signals on velocities are also treated as "eddy" variations, thus the EKE largely reflects a mixture of seasonal mean flows and transient eddies. In contrast, in a recent study focusing on intraseasonal sea level variations in the SCS, "eddy" is defined as the variability on intraseasonal timescale (Zhuang et al., 2010). The latter definition clearly displays two high-energy bands, consistent with the two major eddy pathways revealed in this study. The contrast suggests that only after the removal of seasonal cycle could eddy pathways appear clearly.

\section{Summary}

In this study, the pathways of oceanic mesoscale signals in the SCS are investigated using MCC method. Both altimetry observations and model simulations exhibit two active MV bands. The northern band is formed by southwestward eddy propagations along 200-2000 $\mathrm{m}$ isobaths south of the NSCS continental slope. The mesoscale signals are strong during the period from winter to spring and relatively weak in summer and autumn, in good agreement with local eddy occurrence rate $\mathrm{Wu}$ 
and Chiang, 2007). The southwestward eddy motions originate west of the Luzon Strait and exist throughout the year, indicating the intrinsic wave-propagation feature with steering effects of the bathymetry. The seasonality of mean flow plays a secondary role in modulating the propagating speed. With the aid of mean flow advections, the velocities of eddy motions reach the maximum in winter and the minimum in summer.

The southern MV band locates southwest off Vietnam coast and is oriented almost in an meridional direction. Different from the propagation feature in the NSCS, the eddy movements along the southern band occur mainly in autumn, become weak in winter and disappear in spring and summer. The southward eddy pathway could not be explained by the advection of mean flow. The meridionally asymmetric WSC in autumn leads to the imbalance of vorticity input between the northern and southern basin. The vorticity transport by the western boundary current induces recirculation and eddy detachments through the inertial process, which is considered to be the mechanism of the southward eddy propagations. After reaching lower latitude in the form of arrested topographic wave, the eddy would decay faster due to the latitudinal dependency of Coriolis force.

In the eastern and central SCS, mesoscale signals mainly show the westward propagation velocities, which are widely observed in the world oceans and attributed to the influence of baroclinic Rossby waves (Morrow et al., 2004; Chelton et al., 2007). Thus the eddy energy generated west of the Luzon Island will transfer westward, resulting in weak local MV. It needs to be stated that few eddies could be 
generated south of $10^{\circ} \mathrm{N}$ due to weak Coriolis force and most of the mesoscale energy is probably propagating in the form of Rossby waves rather than eddies (Chelton et al., 2007). So the pathways of MV nearby Nansha Islands might not be well detected because the phase speed of Rossby waves is higher than $30 \mathrm{~cm} / \mathrm{s}$ (Gan and Cai, 2001). This region exhibits very weak MV and is dynamically unimportant to this study.

Instead of the previous Lagrangian descriptions on the movement of individual eddies in the SCS (Wang et al., 2003; Xiu et al., 2010), the space-time correlation analysis used in this study provides an Eulerian description of eddy pathways, which is important information for gaining further understanding on eddy dynamics. In despite of discrepancies in magnitude, OFES reproduces both the observed MV and its propagation features quite well. Inter-comparison between observations and simulations validates not only the performance of OFES but also the reliability of MV propagations revealed by the MCC method.

Acknowledgments. The altimeter products were produced by SSALTO/DUACS and distributed by AVISO with support from CNES. The OFES simulation was conducted on the Earth Simulator under the support of JAMSTEC. This work was supported by ****. The authors are grateful to two anonymous reviewers for their thoughtful comments on the manuscript. 


\section{References}

Bryan K. 1963. A numerical investigation of a non-linear model of a wind-driven ocean. J. Atmos. Sci., 20: 594-606.

Carrère L, Lyard F. 2003. Modeling the barotropic response of the global ocean to atmospheric wind and pressure forcing - comparisons with observations. Gephys. Res. Lett., 30(6): 1275, doi:10.1029/2002GL01647.

Chelton D B, Schlax M G, Samelson R M, de Szoeke R A. 2007. Global observations of large oceanic eddies. Geophys. Res. Lett., 34, L15606, doi:10.1029/2007GL030812.

Chen G, Hou Y, Chu X, Qi P, and Hu P. 2009. The variability of eddy kinetic energy in the South China Sea deduced from satellite altimeter data. Chin. J. Oceanol. and Limnol., 27(4): 943-954.

Chu P C, Fan C W, Lozano C J, Kerling J L. 1998. An airborne expendable bathythermograph survey of the South China Sea, May 1995. J. Geophys. Res., 103: 21 637-21652.

Csanady, G. 1978: The Arrested Topographic Wave. J. Phys. Oceanogr., 8: 47-62.

Domingues C M, Goncalves G A, Ghisolfi R D, Garcia C A E. 2000. Advective surface velocities derived from sequential infrared images in the southwestern Atlantic Ocean. Remote Sens. Environ., 73: 218-226.

Ducet N, Le Traon P-Y, and Reverdin G. 2000. Global high resolution mapping of ocean circulation from TOPEX/Poseidon and ERS-1/2. J. Geophys. Res., 105: 19 477-19 498.

Emery W, Thomas A C, Collins M J, Crawford W R, Mackas D L. 1986. An objective method for computing advective surface velocities from sequential infrared satellite images. J. Geophys. Res. 91: 12 865-12 878

Fu L-L. 2006. Pathways of eddies in the South Atlantic Ocean revealed from satellite altimeter observations. Geophys. Res. Lett., 33, L14610, doi:10.1029/2006GL026245.

Fukumori I, Raghunath R, Fu L-L. 1998. Nature of the global large scale sea level variability in relation to atmospheric forcing: A modeling study. J. Geophys. Res., 103: 5 493- 5512.

Gan J, Li H, Curchitser E N, Haidvogel D B. 2006. Modeling South China Sea circulation: Response to seasonal forcing regimes. J. Geophys. Res., 111: C06034, doi:10.1029/2005JC003298.

Gan Z, Cai S. 2001. Geographical and seasonal variability of Rossby radii in South China Sea. J. Tropical Oceanology, 20 (1): 1 - 9 (in Chinese, English abstract). 
He Z, Wang D, Hu J. 2002. Features of eddy kinetic energy and variations of upper circulation in the South China Sea. Acta Oceanol. Sin., 21: 305-314.

Hu J, Kawamura H, Hong H, Kobashi F, Wang D. 2001. 3 6 month variation of sea surface height in the South China Sea and its adjacent ocean. J. Oceanogr., 57: 69-78.

Jia Y, Liu Q, Liu W. 2005. Primary study of the mechanism of eddy shedding from the Kuroshio Bend in Luzon Strait. J. Oceanogr., 61: 1017-1027.

Li L, Nowlin W D, Su J. 1998. Anticyclonic rings from the Kuroshio in the South China Sea. Deep-Sea Res. Part I, 45: 1469-1482.

Li L, Jing C, Zhu D. 2007. Coupling and propagating of mesoscale sea level variability between the western Pacific and the South China Sea. Chin. Sci. Bull., 52(12): 1 699-1 707.

Liu Q, Jia Y, Liu P, Wang Q. 2001a. Seasonal and Intraseasonal Thermocline Variability in the Central South China Sea. Geophys. Res. Lett., 28(23): 4 467-4 470.

Liu Z, Yang H, Liu Q. 2001b. Regional dynamics of seasonal variability in the South China Sea. J. Phys. Oceanogr., 31: 272-284.

Lyard F, Lefebre F, Letellier T. 2006. Modelling the global ocean tides: Modern insights from FES2004, Ocean Dyn., 56: 394-415.

Masumoto Y, Sasaki H, Kagimoto T, Komori N, Ishida A, Sasai Y, Miyama T, Motoi T, Mitsudera H, Takahashi K, Sakuma H, Yamagata T. 2004. A Fifty-Year Eddy-Resolving Simulation of the World Ocean-Preliminary Outcomes of OFES (OGCM for the Earth Simulator). J. Earth Simulator, 1: 31-52.

Metzger E.J. 2003. Upper ocean sensitivity to wind forcing in the South China Sea. J. Oceanogr., 59: $783-798$.

Morrow R, Birol F, Griffin D, Sudre J. 2004. Divergent pathways of cyclonic and anti-cyclonic ocean eddies. Geophys. Res. Lett., 31, L24311, doi:10.1029/2004GL020974.

Pascual A, Faugère Y, Larnicol G, Le Traon P. Y. 2006. Improved description of the ocean mesoscale variability by combining four satellite altimeters. Geophys. Res. Lett., 33, L02611, doi:10.1029/2005GL024633.

Pacanowski R C, Griffies S M. 2000. MOM 3.0 Manual. Geophysical Fluid Dynamics Laboratory/National Oceanic and Atmospheric Administration, 680pp.

Qu T, Du Y, Gan J, Wang D. 2007. Mean seasonal cycle of isothermal depth in the South China Sea. J. Geophys. Res., 112, C02020, doi:10.1029/2006JC003583.

Richman J G, Wunsch C, Hogg N G. 1977. Space and time scales and mesoscale motion in the sea. 
Rev. Geophys., 15: 385-420.

Rio M-H, Schaeffer P, Lemoine J-M, Hernandez F. 2005. Estimation of the ocean Mean Dynamic Topography through the combination of altimetric data, in-situ measurements and GRACE geoid: From global to regional studies. Proceedings of the GOCINA international workshop, Luxembourg.

Sasaki H, Sasai Y, Nonaka M, Masumoto Y, Kawahara S. 2006. An eddy-resolving simulation of the quasi-global ocean driven by satellite-observed wind field: Preliminary outcomes from physical and biological fields. J. Earth Simulator, 6: 35-49.

Schlax M G, Chelton D B. 1994. Aliased tidal errors in Topex/Poseidon sea surface height data. $J$. Geophys. Res., 99 (24): 761- 24775.

Shaw P-T. 1991. Seasonal variation of the intrusion of the Philippine Sea water into the South China Sea. J. Geophys. Res., 96: 821-827.

Volkov D L, Larnicol G, Dorandeu J. 2007. Improving the quality of satellite altimetry data over continental shelves. J. Geophys. Res., 112, C06020, doi:10.1029/2006JC003765.

Wang D, Wang W, Shi P, Guo P, Gan Z. 2003a. Establishment and adjustment of monsoon-driven circulation in the South China Sea. Science in China, Ser. D, 46: 173-191.

Wang G., Su J, Chu P C. 2003b. Mesoscale eddies in the South China Sea observed with altimeter data. Geophys. Res. Lett., 30, 2121, doi:10.1029/2003GL018532.

Wang G, Chen D, Su J. 2008. Winter Eddy Genesis in the Eastern South China Sea due to Orographic Wind Jets. J. Phys. Oceanogr., 38: 726-732.

Wang L P, Koblinsky C J, Howden S. 2000. Mesoscale variability in the South China Sea from the TOPEX/Poseidon altimetry data. Deep Sea Res., Part I, 47: 681-708.

Wu C-R, Chiang T-L. 2007. Mesoscale eddies in the northern South China Sea. Deep Sea Res., Part II, 54: 1575- 1588.

Wyrtki K. 1961. Physical oceanography of the southeast Asian waters, Scientific results of marine investigations of the South China Sea and the Gulf of Thailand, NAGA Rep. 2. Scripps Inst. of Oceanogr., La Jolla, California. 195p..

Wyrtki K, Magaard L, Hager J. 1976. Eddy energy in the oceans. J. Geophys. Res., 81: 2641-2646.

Xie S-P, Xie Q, Wang D, Liu W T. 2003. Summer upwelling in the South China Sea and its role in regional climate variations. J. Geophys. Res., 108(C8), 3261, doi:10.1029/2003JC001867.

Xie S-P, Chang C-H, Xie Q, Wang D. 2007. Intraseasonal variability in the summer South China 
Sea: Wind jet, cold filament, and recirculations. J. Geophys. Res., 112, C10008, doi:10.1029/2007JC004238.

Xiu P, Chai F, Shi L, Xue H, Chao Y. 2010. A census of eddy activities in the South China Sea during 1993-2007. J. Geophys. Res., 115, C03012, doi:10.1029/2009JC005657.

Xu X Z, Qiu Z, Chen H C. 1982. The general descriptions of the horizontal circulation in the South China Sea. In: Proceedings of the 1980 Symposium on Hydrometeorology of the Chinese Society of Oceanology and Limnology, Sci. Press, Beijing. p. 137-145 (in Chinese with English abstract).

Yuan D, Han W, Hu D. 2006. Surface Kuroshio path in the Luzon Strait area derived from satellite remote sensing data. J. Geophys. Res., 111, C11007, doi:10.1029/2005JC003412.

Zhuang W, Xie S-P, Wang D, Taguchi B, Aiki H, Sasaki H. 2010. Intraseasonal variability in sea surface height over the South China Sea. J. Geophys. Res., 115, C04010, doi:10.1029/2009JC005647. 
Figure List:

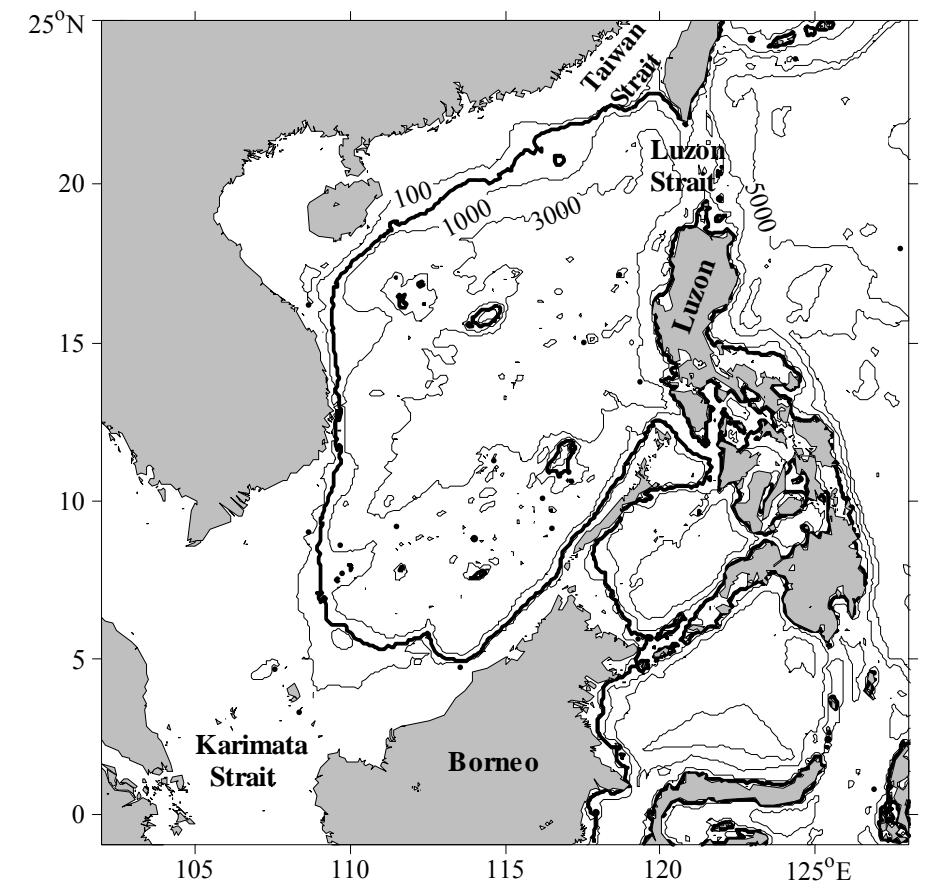

Figure 1. Bottom topography of the South China Sea derived from the ETOPO5, with the 100, 200, 1000, 3000 and $5000 \mathrm{~m}$ isobaths shown. The bold contours represent the $200 \mathrm{~m}$ isoline. 

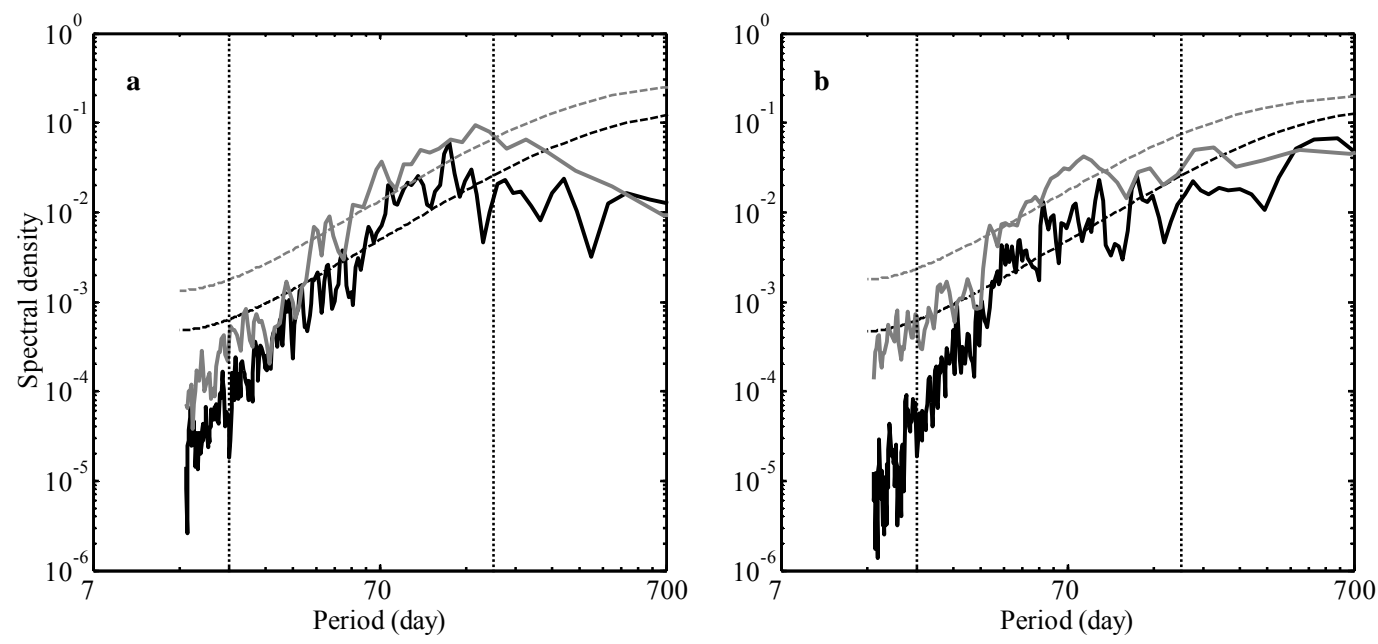

Figure 2. The power spectra of SLAs derived from altimeter observations (black line) and OFES simulations (gray line) at the zones with high eddy occurrence: (a) south of the NSCS continental slope; (b) east of Vietnam coast. The annual and semiannual harmonics have been removed from the SLAs. Dashed lines and dotted lines represent the $95 \%$ confidence level and cutoff period for mesoscale signals. The positions selected for spectrum analysis are shown as green triangles in fig. $3 a$. 

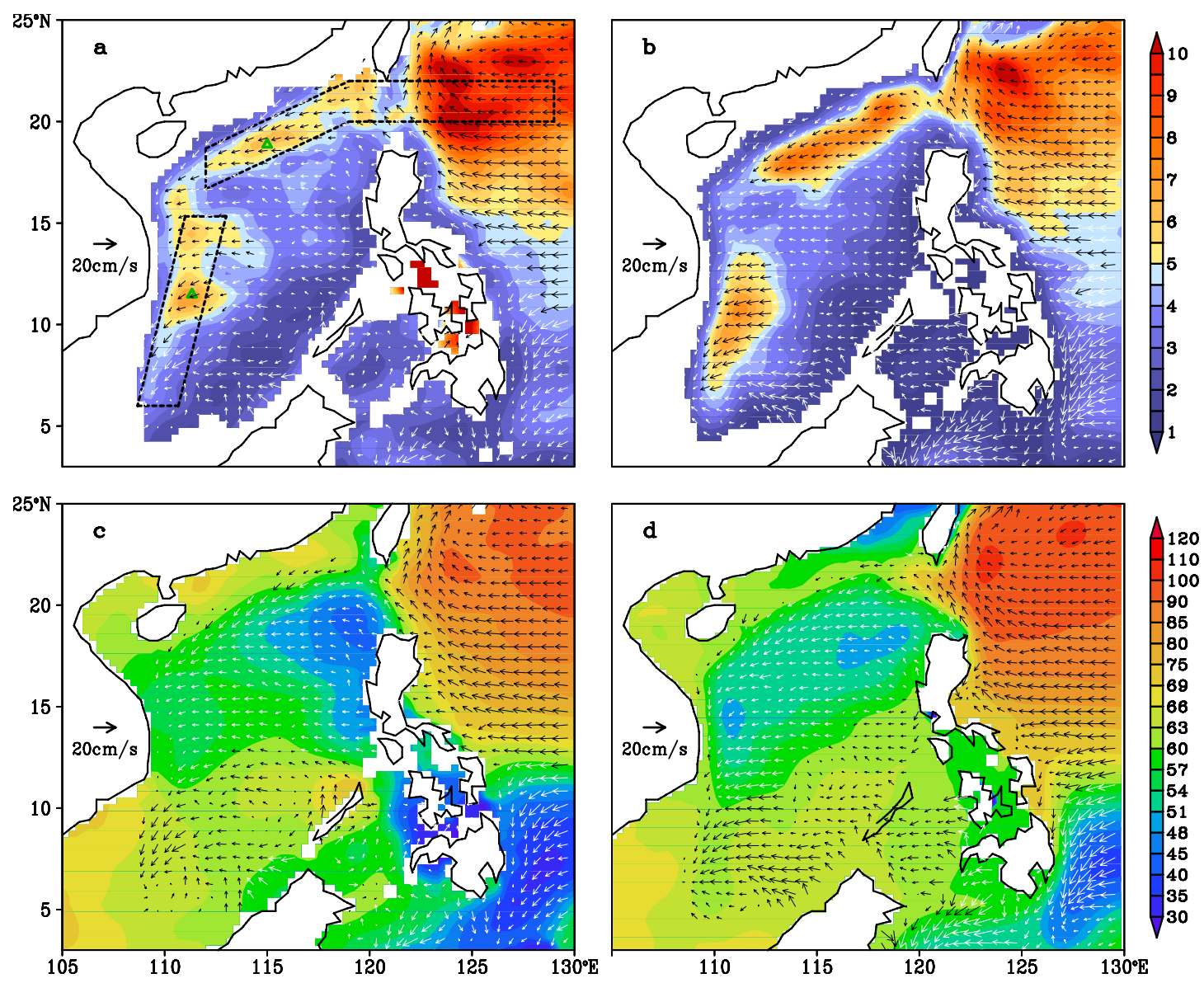

Figure 3. Annual mean standard deviation of sea level mesoscale signals (color shading, unit: $\mathrm{cm}$ ) and the propagation velocities of the signals (vector) derived from (a) altimeter observations and (b) OFES simulations. (c) The same vectors as (a) superimposed on the annual mean absolute dynamic topography (unit: $\mathrm{cm}$ ). (d) The same vectors as (b) superimposed on the annual mean SSH from OFES (unit: $\mathrm{cm}$ ). The two colors of the arrows are for easy viewing. 

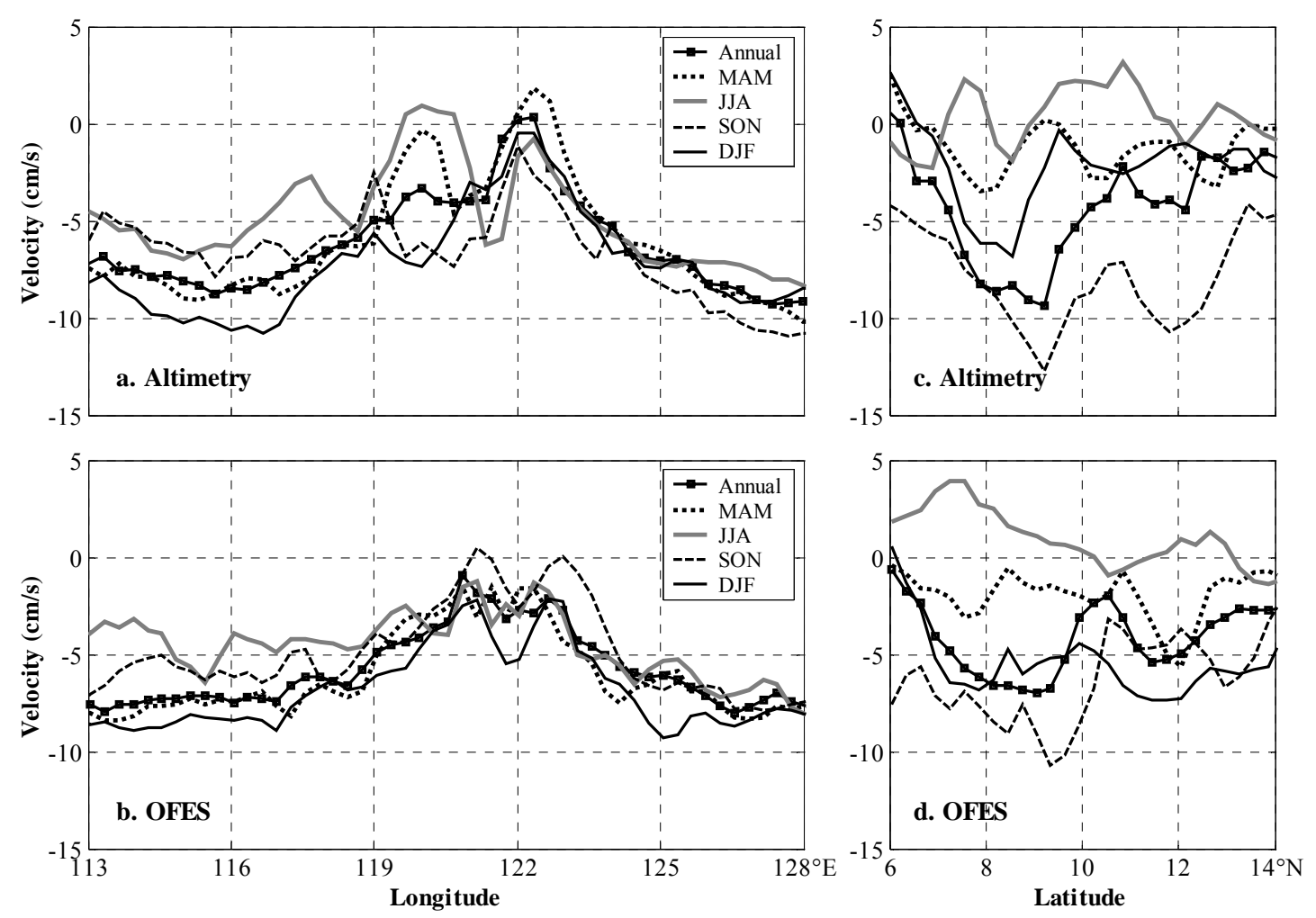

Figure 4. The propagation velocities of mesoscale signals along two strips shown in fig. 3a: (a) altimeter observations along the northern band; (b) OFES simulations along the northern band; (c) altimeter observations along the southern band; (d) OFES simulations along the southern band. The velocities are parallel to the strips and averaged in meridional direction for the northern one and in zonal direction for the southern one. 

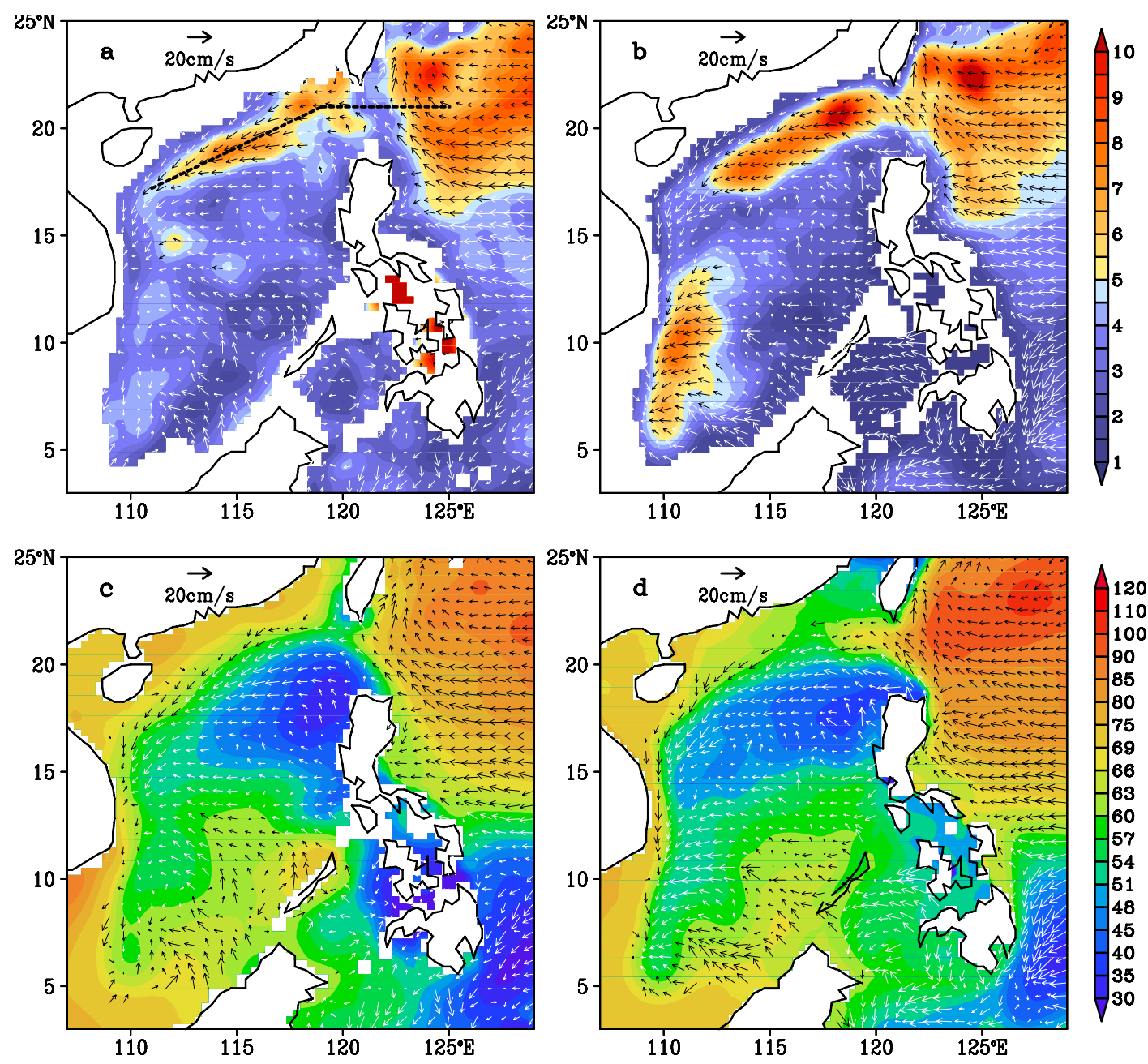

Figure 5. The same as fig. 3, but for the results in winter. 

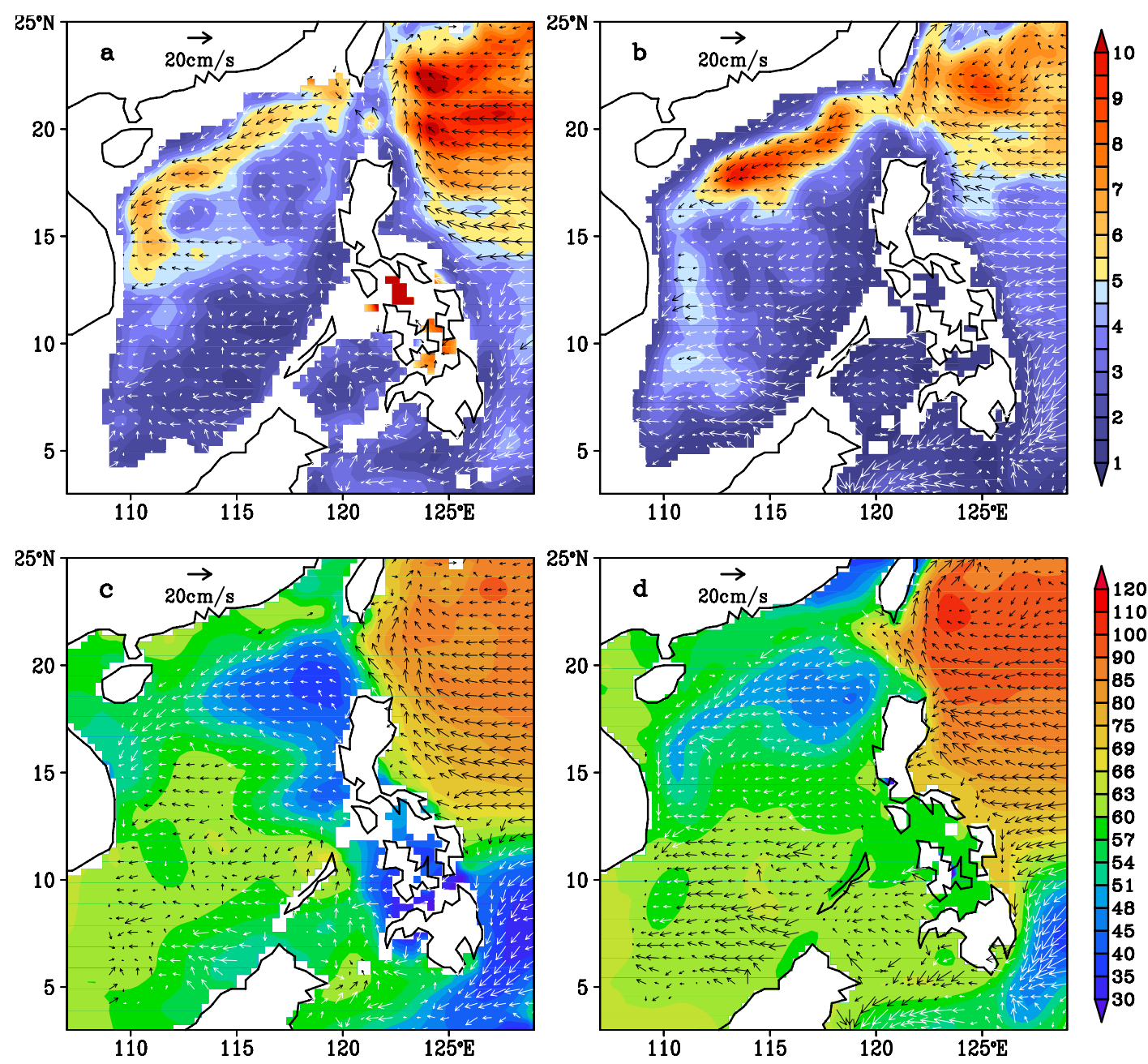

Figure 6. The same as fig. 3, but for the results in spring. 

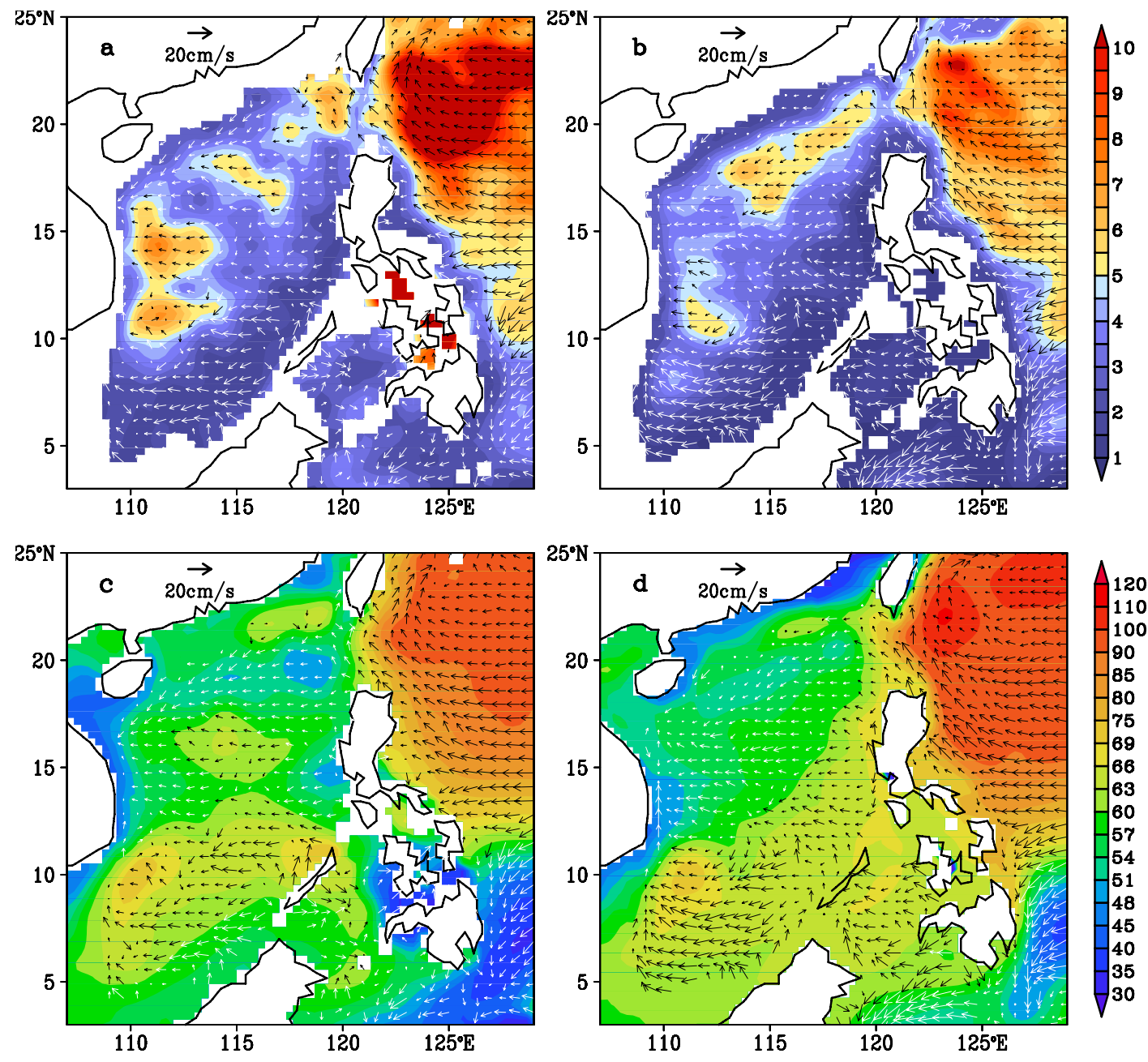

Figure 7. The same as fig. 3, but for the results in summer. 

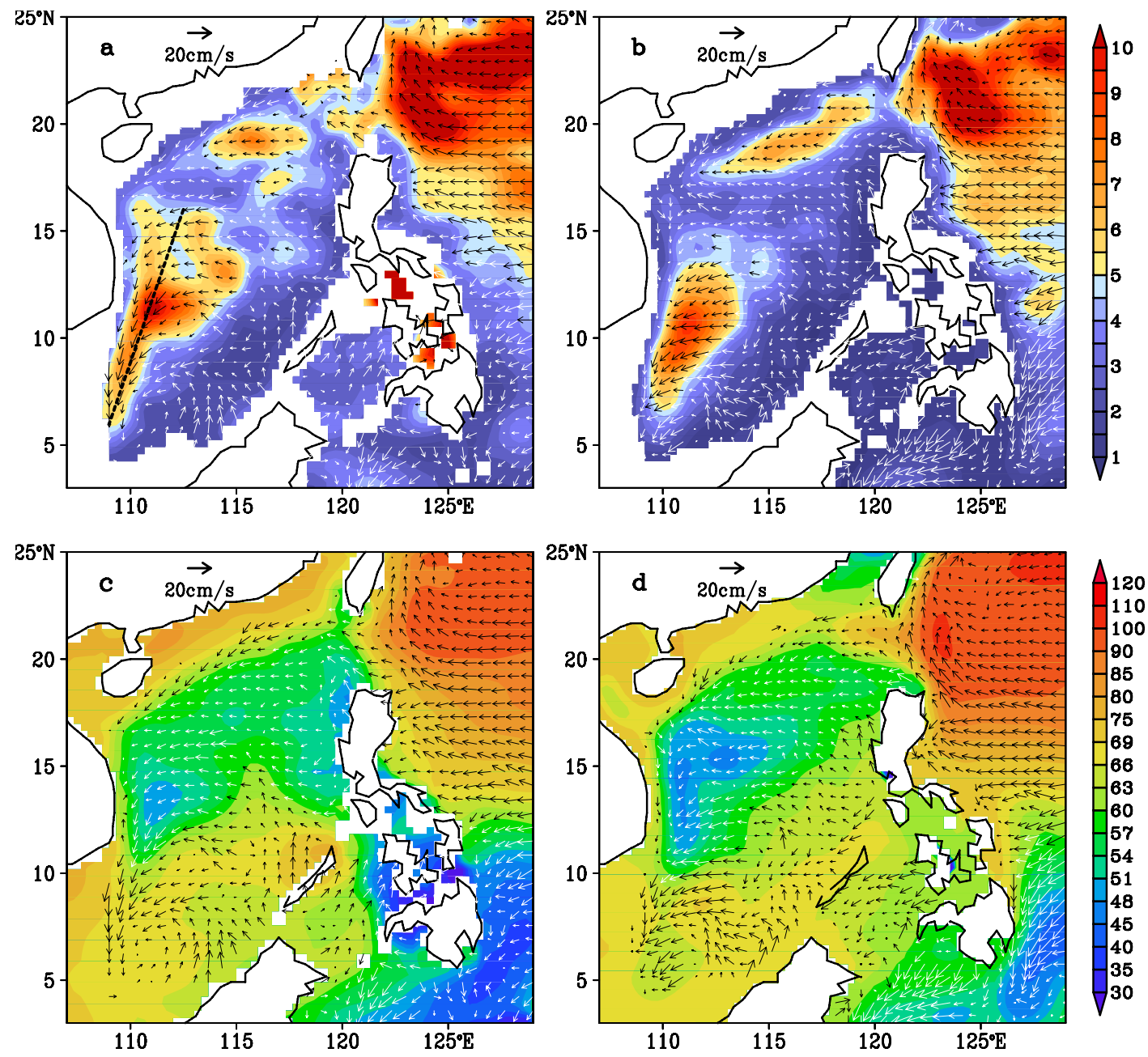

Figure 8. The same as fig. 3, but for the results in autumn. 

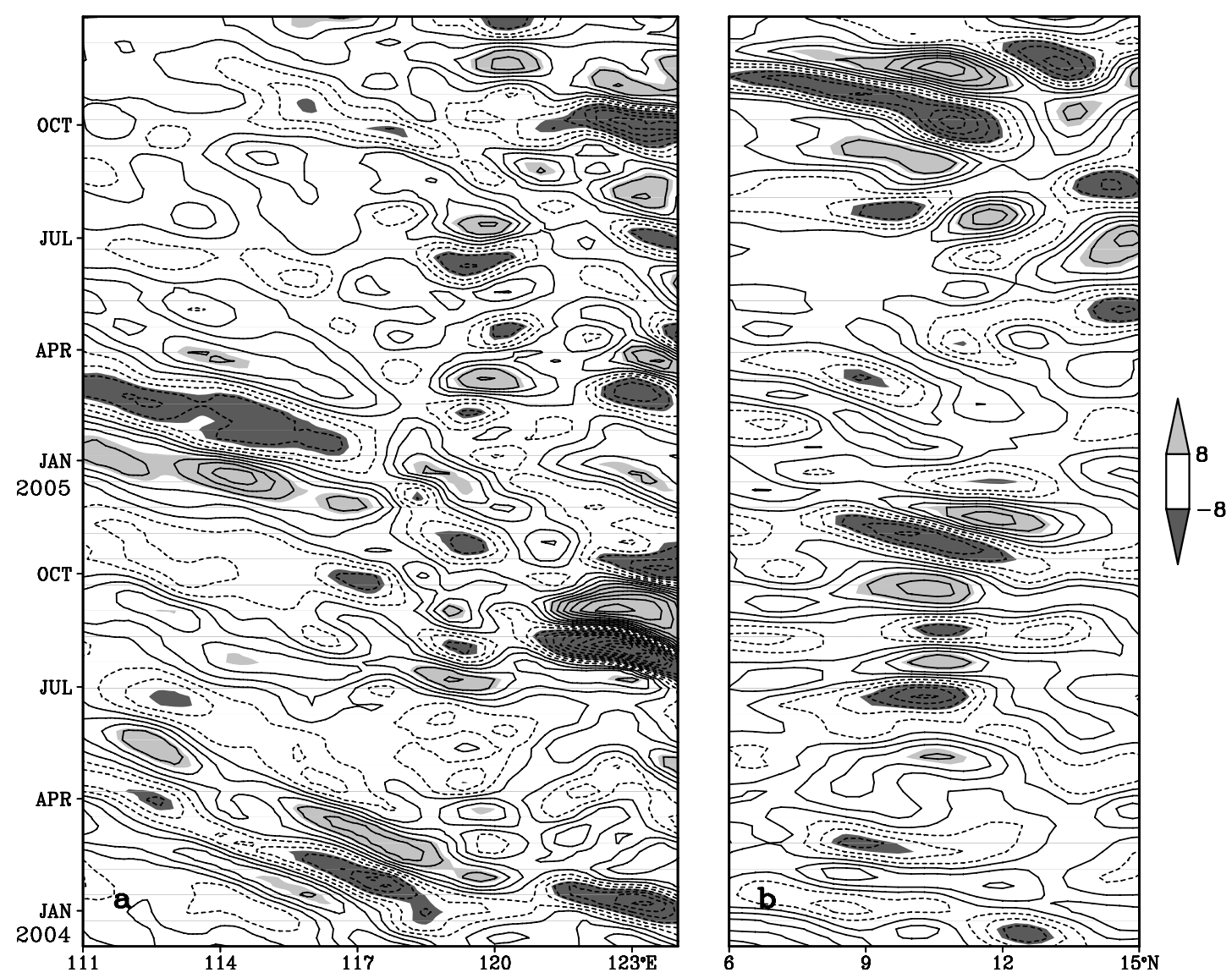

Figure 9. Hovmöller diagrams of observed $\mathrm{SSH}$ mesoscale signals (unit: $\mathrm{cm}$ ) along two high-variance bands in the SCS: (a) longitude-time plot along the northern line shown in fig. 5a during 2004-2005; (b) latitude-time plot along the southern line shown in fig. 8a during 2004-2005. 


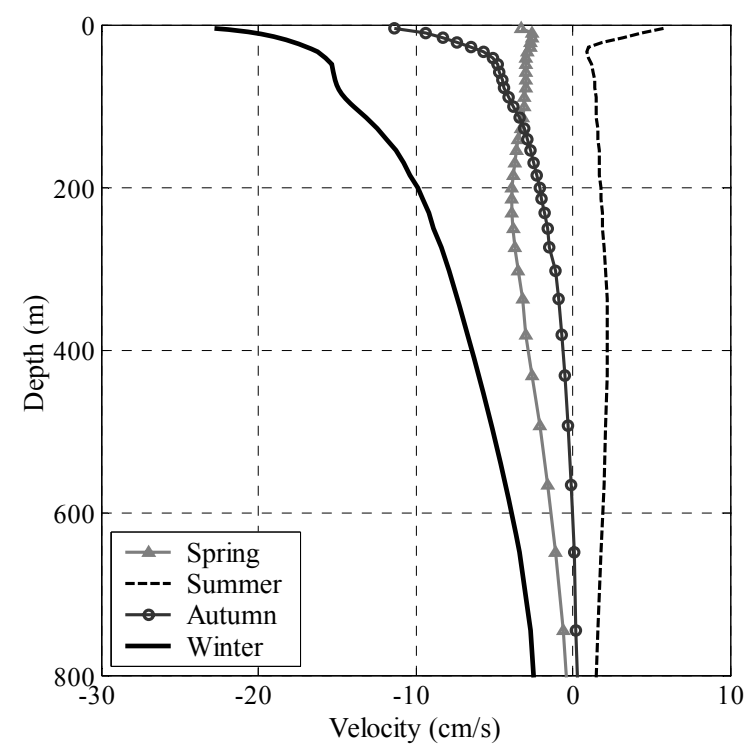

Figure 10. The flow velocities along the northern line shown in fig. 5a (averaged between $\left.111-119^{\circ} \mathrm{E}\right)$, based on OFES simulations. 